\title{
Влияние экстракта коры дуба (Quercus cortex) и комплекса веществ ингибиторов Quorum sensing на метаболические процессы, протекаемые в желудочно-кишечном тракте крупного рогатого скота
}

\author{
К.С. Кондрашова, Д.Б. Косян, К.Н. Атландерова \\ Федеральный научный центр биологических систем и агротехнологий Российской академии наук (2. Оренбург)
}

\begin{abstract}
Аннотация. Одной из тенденций в практике кормления животных сельского хозяйства является использование антибиотиков в качестве кормовых добавок. Но они способны оказывать негативное влияние как на микрофлору животных, так и на состояние окружающей среды. Поэтому возрастает интерес к поиску альтернативных кормовых добавок. В связи с этим в статье представлены результаты исследования, проведённого с целью определения воздействия экстракта Quercus cortex (I опытная группа) и комплекса веществ ингибиторов Quorum sensing (II опытная группа) на переваримость кормового субстрата и обмен веществ у крупного рогатого скота как альтернативных антибиотикам кормовых добавок. В ходе эксперимента было выявлено, что использованные вещества положительно влияют на скорость обмена азота, отмечено нарастание содержания аммиака в рубце животных I и II опытных групп до 2,88 \% и 8,80 \% (P $\leq 0,001)$ через 3 часа; 6,08 \% и 11,08 \% $(\mathrm{P} \leq 0,001)$ - через 6 часов соответственно. Также способствуют лучшей перевариваемости веществ, в результате масса переваренного сухого вещества опытных групп имела превосходство относительно контрольной на $3,02 \%$ и 9,54 \%, протеина - на 7,28 \% и 8,23 \%, клетчатки - на 7,73 \% и 11,0 \% в I и II группах соответственно. Помимо этого, в ходе наших исследований был установлен положительный баланс азота, кальция во всех сравниваемых группах. На метаболизм фосфора более выраженное влияние оказал препарат ингибиторов Quorum sensing, чем экстракт Quercus cortex. При этом отложение фосфора в I группе по сравнению с контролем было выше на 16,99 \%, а во II - на 19,69 \%. Положительный эффект исследуемых веществ показывает их перспективы в практике животноводства.
\end{abstract}

Ключевые слова: крупный рогатый скот, кормление, переваримость, Quorum sensing, экстракт Quercus cortex, кормовые добавки.

UDC 636.085:636.085.25

Effect of oak bark extract (Quercus cortex) and a complex of substances inhibitors Quorum sensing on metabolic processes occurring in the gastrointestinal tract of cattle

\author{
Kristina S Kondrashova, Dianna B Kosyan, Kseniya N Atlanderova \\ Federal Research Centre of Biological Systems and Agricultural Technologies of Russian Academy of Sciences (Orenburg, Russia)
}

Summary. One of trends in the practice of animal feeding in agriculture is the use of antibiotics as feed additives. However, they can have a negative impact on both the microflora of animals and the state of the environment. Therefore, there is a growing interest in finding alternative feed additives. In this regard, the article presents the results of a study conducted to determine the effect of Quercus cortex extract (I experimental group) and a complex of Quorum sensing inhibitors (II experimental group) on the digestibility of the feed substrate and metabolism in cattle, as an alternative feed additives to antibiotics. During the experiment, it was found that substances used positively affect the rate of nitrogen exchange, and an increase in the ammonia content in the rumen of animals of experimental groups I and II was noted to $2,88 \%$ and $8,80 \%$ ( $\mathrm{P} \leq 0,001$ ) (after 3 hours); 6,08\% and 11,08\% ( $\mathrm{P} \leq 0,001)$ (after 6 hours), respectively. They also contribute to better digestibility of substances, as a result, the mass of digested dry matter of the experimental groups was superior to the control group by $3,02 \%$ and $9,54 \%$, protein by $7,28 \%$ and $8,23 \%$, fiber by $7,73 \%$ and $11,0 \%$, in groups I and II, respectively. In addition, in the course of our research, a positive 
balance of nitrogen and calcium was established in all the compared groups. The phosphorus metabolism was more strongly influenced by the quorum sensing inhibitor drug than the Quercus cortex extract. At the same time, the deposition of phosphorus in group I compared to the control was higher by $16,99 \%$, and in group II by $19,69 \%$. The positive effect of the studied substances shows their prospects in the practice of animal husbandry.

Key words: cattle, digestibility, Quorum sensing, Quercus cortex extract, feeding, feed additives.

\section{Введение.}

Современное животноводство активно использует антибиотики в качестве кормовой добавки для стимулирования роста скота, повышения продуктивности путём ограничения виляния патогенной флоры на пищеварительные процессы жвачных животных (Reti KL et al., 2013; Valero MV et al., 2014). Однако использование антибактериальных препаратов негативно сказывается на состоянии окружающей среды (Gaggia $\mathrm{F}$ et al., 2010).

Ввиду этого возникает потребность в поиске более натуральных кормовых добавок, альтернативных антибиотикам (Khan RU et al., 2016). Во многих исследованиях сообщалось о положительном эффекте использования растительных экстрактов в качестве хорошей альтернативы антибактериальным кормовым добавкам (Cruz OTB et al., 2014). Такой эффект обусловлен снижением нагрузки воздействия патогенных бактерий, улучшением потребления сухого вещества и эффективности преобразования корма, повышением эффективности использования питательных веществ, что в целом способствует росту и здоровью, а также производству мяса и молока у жвачных животных (Arowolo MA and He J, 2018). К их числу относятся и препараты, производимые из экстракта Quercus cortex (ЭQc) (Deryabin DG and Tolmacheva AA, 2015). Установлено, что комплекс растительных молекул, присутствующих в Э $Q c$, проявил выраженную способность к подавлению Quorum sensing (QS) у бактерий, являющимся одним из механизмов, обуславливающих резистентность микроорганизмов. При этом биологическая активность экстрактов лекарственных растений, подавляющая систему QS, определяется суммарным эффектом присутствующих в них малых молекул (Атландерова К.Н. и др., 2019). Вследствие чего проведённые нами исследования являются актуальными и имеют огромный потенциал для сельскохозяйственной отрасли.

\section{Цель исследования.}

Изучение влияния Э $Q c$ и комплекса веществ ингибиторов QS на переваримость кормового субстрата и обмен веществ у крупного рогатого скота, и сравнение их активности.

\section{Материалы и методы исследования.}

Объект исследования. Бычки красной степной породы в возрасте 14 месяцев.

Обслуживание животных и экспериментальные исследования были выполнены в соответствии с инструкциями и рекомендациями Russian Regulations, 1987 (Order No. 755 on 12.08.1977 the USSR Ministry of Health) и «The Guide for Care and Use of Laboratory Animals (National Academy Press Washington, D.C. 1996)». При выполнении исследований были предприняты усилия, чтобы свести к минимуму страдания животных и уменьшения количества используемых образцов.

Схема эксперимента. Исследования были проведены на производственном участке Покровского сельскохозяйственного колледжа-филиала ФГБОУ ВО «Оренбургский государственный аграрный университет».

В качестве препарата, содержащего ингибиторы QS, использовался водный ЭQc (AО «Красногорсклексредства», г. Красногорск, Россия) и специально приготовленный препарат ингибиторов QS (ИQS) с подтверждённым анти-QS эффектом (Патент RU 2719621, 2020).

Для получения данного препарата смешивали кору дуба (20 г) с водой (200 мл), фильтровали после кипячения в течение 30 минут, проводили отжим и центрифугирование (15 минут, 2000 об./мин), затем добавляя воду, доводили исходный объём до 200 мл. 
Препарат ИQS получали путём смешивания соответствующих навесок веществ (4-(3-гидрокси-1-пропенил)-2-метокси-фенол - 50 \%; 3,4,5-триметилгидроскифенол - 20 \%; 4-пропил-1,3бензолдиол - 15,5 \%; 4-гидрокси-3-метоксибензальдегида - 5,9 \%; 7-гидрокси6-метокси-2Н-1бензопиран-2-он - 5,3%; 2Н-1-бензопиранон-2 - 3,3\%) с дистиллированной водой, после чего диспергировали в изотоническом растворе с помощью ультразвуковой обработки (30 мин, $\mathrm{f}-35$ кГц, $\mathrm{N}-$ 300 Вт, А - 10 мкА).

В период исследований животные были разделены на 3 группы (n=3) методом параналогов, подготовительный период длился 10 суток, после которого животных перевели на 8 суток в условия основного учётного периода. Контроль - основной рацион (ОР), I опытная - ОР+ЭQс 0,64 мл/кг, II опытная - OP+ИQS 0,81 мл/кг. ОР, соответствующий нормам кормления (Калашников А.П. и др., 2003), составляли на основе кормов хозяйства. Рацион включал сено суданки 2,5 кг/гол./сут; сено люцерны 3,0 кг/гол./сут; силос кукурузный 8,0 кг/гол./сут; отруби пшеничные 1,0 кг/гол./сут; ячмень дроблёный 1,0 кг/гол./сут; жмых подсолнечный 0,5 кг/гол./сут.

Показатели обмена азотистых метаболитов в рубцовом содержимом (остаточный и общий азот) устанавливали методом Къельдаля по методике К.К. Ахажанова (2016); аммиачный азот определяли микродиффузным методом по Конвею.

При исследовании переваримости питательных веществ проведён балансовый опыт. По методикам зоотехнического анализа (Лукашик А.А. и Тащилин В.А., 1965) был проведён учёт съеденных кормов и их остатков, для этого в ходе учётного периода были отобраны средние пробы кала $(10 \%)$ и мочи (3\%) от общего количества в сутки. Массовая доля сухого вещества, сырого протеина (ГОСТ 13496.4-93), массовая доля сырого жира (ГОСТ 13496.15-2016), массовая доля сырой клетчатки (ГОСТ 13496.2-91), кальция (ГОСТ 26570-95), фосфора (ГОСТ 26657-97) определялась в пробах кала. В пробах мочи (3 \% от общего количества) определяли удельный вес, минеральные вещества, содержание азота по методике П.Т. Лебедева и А.Т. Усович (1976).

Оборудование и технические средства. Исследования проводились на базе Испытательного центра ЦКП ФГБНУ ФНЦ БСТ РАН. Весы лабораторные электронные МВ 210-А (3АО «Сартогосм», Россия), аппарат Сокслета (Полтавский завод медицинского стекла, Украина), шкаф сушильный ШС-80-01-СПУ («Смоленское СКТБ СПУ», Россия), анализатор азота по Къельдалю (Velp Scientifika, Италия).

Статистическая обработка. Полученные результаты исследований были обработаны с применением офисного программного комплекса «Microsoft Office» с применением программы «Excel» («Microsoft», США) с обработкой данных в «Statistica 10.0» («Stat Soft Inc.», США), включая определение средней арифметической величины (M), стандартной ошибки средней (m). Статистическую оценку проводили с помощью t-критерия Стьюдент.

\section{Результаты исследований.}

Рубцовое пищеварение. Ввиду того, что эффективность пищеварения напрямую зависит от микробного состава рубца, на начальном этапе нами была оценена интенсивность бактериальных процессов, выраженная в измерении азотистых метаболитов.

Поскольку некоторая доля азота, поступающая в составе корма, модифицируется в аммиак, то по его содержанию можно говорить об обмене азота, который в свою очередь даёт возможность судить о характере течения пищеварительного процесса. Также было установлено увеличение содержания аммиака в рубце животных как в I, так и во II опытных группах на 2,88 \% и 8,80 \% $(\mathrm{P} \leq 0,001)$ соответственно после 3 часов экспозиции. Такая же тенденция наблюдается после 6-часового периода. При этом концентрация аммиака в содержимом рубца животных I группы превосходила кон-

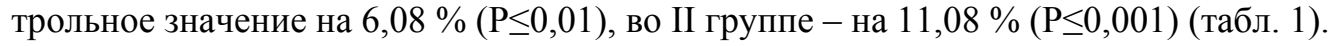


Животноводство и кормопроизводство 2020 T. 103 № 4/Animal Husbandry and Fodder Production 2020 Vol. 103 Is. 4

Теория и практика кормления

Таблица 1. Содержание азотистых метаболитов в рубце животных, ммоль/л Table 1 . The contents of nitrogenous metabolites in the rumen of animals, $\mathbf{m m o l} / \mathbf{l}$

\begin{tabular}{|c|c|c|c|c|}
\hline $\begin{array}{c}\text { Время отбора } \\
\text { пробы, час/ } \\
\text { Sampling time, hours }\end{array}$ & Группа/ Group & $\begin{array}{c}\text { Общий азот/ } \\
\text { Total nitrogen }\end{array}$ & $\begin{array}{c}\text { Белковый } \\
\text { азот/ Protein } \\
\text { nitrogen }\end{array}$ & $\begin{array}{c}\text { Небелковый } \\
\text { aзот/ Non protein } \\
\text { nitrogen }\end{array}$ \\
\hline \multirow{2}{*}{3} & контрольная/control & $221,9 \pm 1,75$ & $167,1 \pm 0,64$ & $54,8 \pm 1,92$ \\
& I & $226,6 \pm 0,86^{*}$ & $173,0 \pm 1,53 * *$ & $53,6 \pm 0,72$ \\
& II & $231,7 \pm 1,65^{* *}$ & $180,3 \pm 0,15^{*} * *$ & $51,4 \pm 1,79 *$ \\
\hline \multirow{2}{*}{6} & контрольная/control & $223,2 \pm 1,12$ & $167,7 \pm 0,89$ & $55,4 \pm 0,78$ \\
& I & $227,6 \pm 1,23^{*}$ & $174,7 \pm 0,33^{*} * *$ & $52,9 \pm 1,16$ \\
& II & $236,7 \pm 1,65^{* * *}$ & $185,4 \pm 0,40^{* *}$ & $51,3 \pm 1,89 * *$ \\
\hline
\end{tabular}

Note: $*-\mathrm{P} \leq 0.05 ; * *-\mathrm{P} \leq 0.01 ; * * *-\mathrm{P} \leq 0.001$

Анализ данных по оценке общего азота через 3 часа экспозиции показал, что включение в рацион ЭQc способствует увеличению содержания общего азота на $2,10 \%(\mathrm{P} \leq 0,05)$, а использование в кормлении ИQS - на 4,41 \% $(\mathrm{P} \leq 0,01)$ в сравнении с контролем. После 6 часов переваривания по данному показателю наибольшие значения общего азота отмечались во II группе. Так, полученный результат был выше на $6,06 \%$ (Р $\leq 0,001)$ относительно контроля.

Значения небелкового азота в рубцовом содержимом опытных животных были ниже, чем в контроле. Так, через 3 часа после экспозиции в I группе - на 2,29 \%, во II - на 6,20 \% $(\mathrm{P} \leq 0,05)$.

После 6-часовой экспозиции концентрация небелкового азота в I группе снизилась на 4,56 \%, во II на $-7,45 \%(\mathrm{P} \leq 0,01)$ в сравнении с контрольной группой. Это, возможно, связано со значительной скоростью переработки азота микробиотой рубца в белок своего тела.

Переваримость питательных вещзеств рациона. Полученные результаты по оценке переваримости питательных веществ позволяют говорить о различном потреблении отдельных питательных веществ подопытными животными. Так, животные I группы интенсивнее потребляли сухое вещество относительно контрольной на 1,53 \%, а животные II - на 3,28 \% (табл. 2).

Таблица 2. Поступление и переваримость основных питательных веществ рационов подопытными животными, г/гол./сут

Table 2. Intake and digestibility of the main nutrients of diets by experimental animals, g/head/day

\begin{tabular}{|c|c|c|c|c|c|c|}
\hline $\begin{array}{c}\text { Показатель/ } \\
\text { Indicator }\end{array}$ & $\begin{array}{c}\text { Сухое } \\
\text { вещество/ } \\
\text { Dry matter }\end{array}$ & $\begin{array}{c}\text { Органиче- } \\
\text { ское веще- } \\
\text { ство/Organi } \\
\text { c matter }\end{array}$ & $\begin{array}{c}\text { Протеин } \\
\text { / Protein }\end{array}$ & $\begin{array}{c}\text { Жир/ } \\
\text { Fat }\end{array}$ & $\begin{array}{c}\text { БЭВ/ } \\
\text { Клетчат- } \\
\text { ка/Fiber }\end{array}$ & $\begin{array}{c}\text { Nitrogen- } \\
\text { free sub- } \\
\text { stances }\end{array}$ \\
\hline \multicolumn{7}{|c|}{ Контрольная/Control } \\
\hline Принято/Accepted & $8557 \pm 49,0$ & $7994 \pm 46,0 \quad 1072 \pm 6,0$ & $248 \pm 10,2$ & $2058 \pm 11,0$ & $4614 \pm 26,0$ \\
Выделено/Selected & $3015 \pm 11,1$ & $2635 \pm 5,0$ & $402 \pm 4,0$ & $78,5 \pm 0,4$ & $954 \pm 10,0$ & $1247 \pm 17,0$ \\
Переварено/Digested & $5542 \pm 50,0$ & $5359 \pm 42,1$ & $670 \pm 3,0$ & $170 \pm 2,2$ & $1104 \pm 7,0$ & $3367 \pm 15,2$ \\
\hline \multicolumn{7}{|c|}{ I группа/I group } \\
\hline Принято/Accepted & $8688 \pm 32,0$ & $8117 \pm 30,0 \quad 1089 \pm 4,1$ & $252 \pm 1,0$ & $2090 \pm 8,0$ & $4685 \pm 17,0$ \\
Выделено/Selected & $2978 \pm 133$ & $2510 \pm 10,1$ & $369 \pm 5,0$ & $75,5 \pm 0,4$ & $900 \pm 7,2$ & $1130 \pm 14,0$ \\
Переварено/Digested & $5711 \pm 106$ & $5606 \pm 24,0$ & $719 \pm 9,0$ & $177 \pm 1,0$ & $1189 \pm 6,0$ & $3555 \pm 9,0$ \\
\hline \multicolumn{7}{|c|}{ ІІ группа/ II group } \\
\hline Принято/Accepted & $8838 \pm 37,2$ & $8256 \pm 35,4$ & $1108 \pm 5,0$ & $257 \pm 1,0$ & $2126 \pm 9,0$ & $4766 \pm 20,1$ \\
Выделено/Selected & $2766 \pm 16,2$ & $2328 \pm 8,0$ & $382 \pm 5,0$ & $73 \pm 1,0$ & $886 \pm 9,0$ & $1091 \pm 24,1$ \\
Переварено/Digested & $6072 \pm 46,0$ & $5928 \pm 38,2$ & $726 \pm 2,0$ & $184 \pm 2,0$ & $1239 \pm 8,0$ & $3675 \pm 41,2$ \\
\hline
\end{tabular}

Масса переваренного сухого вещества опытных групп имела превосходство относительно контрольной на 3,02 \% и 9,54 \%, протеина - на 7,28 \% и 8,23 \%, клетчатки - на 7,73 \% и 11,0 \% со- 
ответственно, что говорит о положительном влиянии ЭQc и ИQS на переваримость питательных веществ.

Таким образом, на основании полученных результатов можно сделать вывод, что использование в кормлении исследуемых добавок может увеличить переваримость питательных веществ рациона.

Обмен азота. Изучение обмена азота в организме животных выявило ряд изменений (табл. 3).

Таблица 3. Среднесуточный баланс азота в организме животных, г/гол. Table 3 . The average daily balance of nitrogen in the organism of animals, $\mathrm{g} / \mathrm{head}$

\begin{tabular}{|l|c|c|c|}
\hline \multicolumn{1}{|c|}{ Показатель / Indicator } & $\begin{array}{c}\text { Контрольная } \\
\text { группа/ Control roup }\end{array}$ & $\begin{array}{c}\text { I группа/ } \\
\text { I group }\end{array}$ & $\begin{array}{c}\text { II группа/ } \\
\text { II group }\end{array}$ \\
\hline Принято/ Accepted & $172 \pm 1,0$ & $174 \pm 0,6$ & $177 \pm 0,8^{*}$ \\
Выделено в кале/ Excreted in the excrement & $64,4 \pm 0,8$ & $59,2 \pm 0,7^{*}$ & $61,2 \pm 0,7^{*}$ \\
Выделено в моче/ Excreted in the urine & $81,5 \pm 0,9$ & $87,1 \pm 2,4^{*}$ & $86,2 \pm 2,1^{*}$ \\
Переварено/ Digested & $107 \pm 1,0$ & $115 \pm 1,0^{*}$ & $116 \pm 0,4^{*}$ \\
Отложено/ Deposited: & & & \\
на 1 голову/ per 1 head & $25,8 \pm 0,9$ & $27,9 \pm 1,4^{*}$ & $29,9 \pm 0,2^{*}$ \\
на 100 кг живой массы/per 100 kg of live weight & $7,60 \pm 2,6$ & $7,90 \pm 0,3$ & $8,21 \pm 0,1$ \\
Коэффициент использования/Utilization rate & & & \\
от принятого/from accepted & $14,9 \pm 0,5$ & $16,0 \pm 0,7$ & $16,9 \pm 0,1$ \\
от переваренного/from digested & $24,0 \pm 0,8$ & $24,3 \pm 0,9$ & $25,8 \pm 0,09$ \\
\hline
\end{tabular}

Примечание: * $-\mathrm{P} \leq 0,05$ в сравнении с контролем.

Note: * $-\mathrm{P} \leq 0.05$ compared to the control

В I и II опытных группах наблюдалось более интенсивное потребление азота с кормом на $1,53 \%$ и на 3,28 \% (P $\leq 0,05)$ соответственно. При этом использование данных добавок в корме сопровождалось достоверным повышением переваривания азота на 7,28 \% $(\mathrm{P} \leq 0,05)$ и 8,23 \% (P $\leq 0,05)$ соответственно. Причём в силу пока ещё не определённых причин выделение азота с мочой в I и II группах достоверно увеличилось до 86,2-87,1 г/гол./сут. Это привело к снижению общего отложения азота в тканях организма животных. Однако в опытных группах данный показатель превосходил контроль на $8,1 \%$ в I и на 15,9 \% $(\mathrm{P} \leq 0,05)$ - во II группах. Подобным образом в опытной группе изменялся и показатель коэффициента использования от принятого азота.

В итоге, баланс азота оказался положительным во всех группах и это можно заметить по его усвояемости в течение суток. О скорости роста молодняка можно судить по интенсивности обмена азота.

Обмен кальичя и фосфора. При проведении исследований были выявлены некоторые изменения в обмене кальция у изучаемых животных (табл. 4).

В ходе проведённых исследований была получена позитивная динамика баланса кальция за счёт уменышения его неэффективного потребления с кормом в процессе переваривания. Так, в I группе усвоилось на 15,6 \% больше кальция, во II - на 19,8 \%, чем в контроле. Коэффициент использования при этом был выше у опытных групп относительно контрольной на 13,8 \% в I и на 15,94 \% - во II.

Поскольку обмен фосфора тесно связан с метаболизмом кальция, то логичным является оценка его содержания в организме животного. На основании того, что опытные группы животных интенсивнее поедали корм, то и поступление фосфора в организм животных I группы было выше на $1,53 \%$; а во II - на 3,26 \%, чем в контроле (табл. 5). 
Таблица 4. Баланс кальция в организме подопытных животных, г/гол./сут Table 4. The balance of calcium in the organism of experimental animals, g/head/day

\begin{tabular}{|l|c|c|c|}
\hline \multicolumn{1}{|c|}{ Показатель/Indicator } & $\begin{array}{c}\text { Контрольная } \\
\text { группа /Control group }\end{array}$ & $\begin{array}{c}\text { I группа/ } \\
\text { I group }\end{array}$ & $\begin{array}{c}\text { II группа/ } \\
\text { II group }\end{array}$ \\
\hline Принято/ Accepted & $69,7 \pm 0,4$ & $70,7 \pm 0,3$ & $71,9 \pm 0,3^{*}$ \\
Выделено в кале/ Excreted in the excrement & $47,0 \pm 0,0$ & $44,7 \pm 2,3$ & $45,0 \pm 2,0$ \\
Выделено в моче/ Excreted in the urine & $0,93 \pm 0,00$ & $0,94 \pm 0,001$ & $0,91 \pm 0,013$ \\
Отложено/ Deposited: & $21,7 \pm 0,4$ & $25,1 \pm 2,6$ & $26,0 \pm 2,3$ \\
$\quad$ на 1 голову/ per 1 head & $6,40 \pm 0,07$ & $7,30 \pm 0,70$ & $7,65 \pm 0,70$ \\
$\quad \begin{array}{l}\text { на 100 кг живой массы/ } \\
\text { per 100 kg of live weight }\end{array}$ & $31,2 \pm 0,4$ & $35,5 \pm 3,5$ & $36,2 \pm 3,0$ \\
Коэффициент использования, \% / & & \\
Utilization rate, \% & & &
\end{tabular}

Примечание: * $-\mathrm{P} \leq 0,05$ в сравнении с контролем.

Note: $*-\mathrm{P} \leq 0.05$ compared to the control

Таблица 5. Баланс фосфора в организме подопытных животных, г/гол. Table 5. The balance of phosphorus in the organism of experimental animals, g/ head

\begin{tabular}{|l|c|c|c|}
\hline \multicolumn{1}{|c|}{ Показатель/Indicator } & $\begin{array}{c}\text { Контрольная } \\
\text { группа/Control group }\end{array}$ & $\begin{array}{c}\text { I группа/ } \\
\text { I group }\end{array}$ & $\begin{array}{c}\text { II группа/ } \\
\text { I group }\end{array}$ \\
\hline Принято/ Accepted & $33,4 \pm 0,2$ & $33,9 \pm 0,1$ & $34,5 \pm 0,1^{*}$ \\
Выделено в кале/ Excreted in the excrement & $27,7 \pm 1,3$ & $20,5 \pm 1,2^{*}$ & $20,8 \pm 0,1^{*}$ \\
Выделено в моче/ Excreted in the urine & $11,5 \pm 1,3$ & $13,4 \pm 1,0$ & $13,7 \pm 0,1$ \\
Отложено/ Deposited: & $3,38 \pm 0,37$ & $3,94 \pm 0,35$ & $4,04 \pm 0,03$ \\
$\quad$ на 1 голову/ per 1 head & & & \\
на 100 кг живой массы/ & & & \\
per 100 kg of live weight & $34,4 \pm 3,8$ & $39,6 \pm 3,2$ & $39,8 \pm 0,1$ \\
\hline
\end{tabular}

Примечание: * $-\mathrm{P} \leq 0,05$ в сравнении с контролем.

Note: ${ }^{*}-\mathrm{P} \leq 0.05$ compared to the control

Результаты проведённых исследований по оценке обмена фосфора не выходили за рамки данных, полученных выше, поэтому можно сделать вывод, что ЭQc мог оказать влияние на обмен фосфора с той разницей, что оно было менее выражено по сравнению с препаратом ИQS. При этом отложение фосфора в І группе по сравнению с контролем было выше на 16,99%, а во II - на 19,69 \%.

\section{Обсуждение полученных результатов.}

Как известно, растения благодаря содержанию различных фитохимических соединений являются потенциальными источниками безопасных и эффективных веществ, обладающих анти-QS активностью (Asfour HZ, 2018), выступая прекрасной альтернативой антибактериальным препаратам. Помимо этого они также положительно влияют на обменные процессы пищеварения у животных (Patra AK and Saxena J, 2010; Hart KJ et al., 2008; Cobellis G et al., 2016; Duskaev GK et al., 2019).

Включение опытных препаратов в рацион животных приводит к повышению уровня перевариваемости питательных веществ корма. Данные результаты подтверждены ранее в исследованиях in vitro (Макаева А.М. и Атландерова К.Н., 2018) и было установлено, что включение ЭQc увеличивает переваримость сухого вещества кормовых добавок. Помимо этого скармливание подопытной птице ЭQс увеличивает поедаемость корма (Казачкова Н.М., 2017а), способствует увели- 
чению живой массы (Фисинин В.И. и др., 2018; Багиров В.А. и др., 2018) и не оказывает отрицательного влияния на минеральный обмен организма птицы (Казачкова Н.М., 2017б). Введение в рацион опытного экстракта положительно влияет на элементный статус микрофлоры рубца, значительно повышая количество кальция и фосфора (Ушаков А.С. и др., 2017). Это - два основных элемента, участвующих в метаболизме крупного рогатого скота (Швиндт В.И., 2006). Нами также было отмечено увеличение усвояемости кальция в опытных группах на 15,7-19,8 \%, фосфора - на $13-16 \%$.

B составе ИQS содержится ванилин и Кумарин, что по данным исследований (Рonnusamy K et al., 2009; Packiavathy IASV et al., 2014) приводит к повышению аппетита, что и демонстрируют полученные результаты. Аналогичный эффект увеличения аппетита наблюдается у поросят, в рацион которых включен 4-гидрокси-3-метоксибензальдегид в составе ароматической композиции (Патент RU 2485801, 2013), вследствие чего повышается уровень суточного потребления корма. В рацион бройлеров включает препарат, содержащий сходные соединения с ИQS (Патент RU 2649812, 2018), что так же приводит к увеличение прироста живой массы.

\section{Выводы.}

Таким образом, в результате исследований было продемонстрировано, что введение в рацион крупного рогатого скота ЭQc и ИQS положительно повлияло на микробиом рубца, на переваримость питательных веществ и на минеральный баланс, что позволяет рекомендовать данные вещества в качестве кормовой добавки для животных сельского хозяйства.

\section{Исследования выполнены в соответствии с планом НИР на 2019-2021 гг. ФГБНУ ФНЦ БСТ РАН (№ 0526-2019-0002)}

\section{Литература}

1. Амортизированная композиция и способ повышения аппетита у поросят с её помощью: пат. 2485801 Рос. Федерация / К. Креспо. Заявл. 27.11.08; опубл. 27.06.13, Бюл. № 18. [Krespo K. Amortizirovannaya kompozitsiya i sposob povysheniya appetita u porosyat s ee pomoshch'yu: pat. 2485801 Ros. Federatsiya. Zayavl. 27.11.2008; opubl. 27.06.13, Byul. № 18. (In Russ)].

2. Ахажанов К.К. Зооанализ кормов: учеб. пособие для с.-х. спец. ВУЗов. Алматы: Эпиграф, 2016. 82 c. [Akhazhanov KK. Zooanaliz kormov: ucheb. posobie dlya s.-kh. spets. VUZov. Almaty: Epigraf; 2016:82 p. (In Russ)].

3. Включение экстракта Quercus cortex в рацион бройлеров изменяет их убойные показатели и биохимический состав мышечной ткани / В.А. Багиров, Г.К. Дускаев, Н.М. Казачкова, Ш.Г. Рахматуллин, Е.В. Яушева, Д.Б. Косян, Ш.А. Макаев, Х.Б. Дусаева // Сельскохозяйственная биология. 2018. T. 53. № 4. C. 799-810. [Bagirov VA, Duskaev GK, Kazachkova NM, Rakhmatullin ShG, Yausheva EV, Kosyan DB, Makaev ShA, Dusaeva KhB. Addition of Quercus cortex extract to broiler diet changes slaughter indicators and biochemical composition of muscle tissue. Sel'skokhozyaistvennaya Biologiya [Agricultural Biology]. 2018;53(4):799-810. (In Russ)]. doi: 10.15389/agrobiology.2018.4.799rus

4. Влияние скармливания растительного экстракта в сочетании с ферментным препаратом на элементный статус микрофлоры рубца крупного рогатого скота / А.С. Ушаков, Г.И. Левахин, Б.С. Нуржанов, А.Ф. Рысаев, А.Г. Мещеряков // Вестник мясного скотоводства. 2017. № 3(99). C. 120-127. [Ushakov AS, Levakhin GI, Nurzhanov BS, Rysayev AF, Meshcheryakov AG. Effect of feeding with vegetative extract in combination with an enzymatic preparation on element status of ruminal microflora of cattle. Herald of Beef Cattle Breeding. 2017;3(99):120-127. (In Russ)].

5. Изменение иммунологических и продуктивных показателей у цыплят-бройлеров под влиянием биологически активных веществ из экстракта коры дуба / В.И. Фисинин, А.С. Ушаков, Г.К. Дускаев Н.М. Казачкова, Б.С. Нуржанов, Ш.Г. Рахматуллин, Г.И. Левахин // Сельскохозяйственная биология. 2018. № 53(2). С. 385-392. [Fisinin VI, Ushakov AS, Duskaev GK, Kazachkova NM, Nurzhanov BS, Rakhmatullin ShG, Levakhin GI. Mixtures of biologically active substances of oak 
bark extracts change immunological and productive indicators of broilers. Sel'skokhozyaistvennaya Biologiya [Agricultural Biology]. 2018;53(2):385-392. (In Russ)]. doi: 10.15389/agrobiology.2018.2.385rus

6. Казачкова H.M. Воздействие экстракта Quercus Cortex на различные виды обмена в организме сельскохозяйственных животных и птицы // Научные исследования: теория, методика и практика: материалы III Междунар. науч.-практ. конф. (Чебоксары, 19 нояб. 2017 г.) / редкол.: О.Н. Широков и др. Чебоксары: ЦНС «Интерактив плюс», 2017б. Т. 1. С. 12-14. [Kazachkova NM. Vozdeistvie ekstrakta Quercus Cortex na razlichnye vidy obmena v organizme sel'skokhozyaistvennykh zhivotnykh i ptitsy (Conference proceedings) Nauchnye issledovaniya: teoriya, metodika i praktika: materialy III Mezhdunar. nauch.-prakt. konf. (Cheboksary, 19 noyab. 2017 g.) redkol.: Shirokov ON et al. Cheboksary: TsNS «Interaktiv plyus»; 2017b;1:12-14. (In Russ)].

7. Казачкова Н.М. Использование природных антибиотиков в рационе сельскохозяйственных животных и птицы // Инновационные технологии в образовании и науке: материалы Междунар. науч.-практ. конф. (Чебоксары, 7 мая 2017 г.) / редкол.: О.Н. Широков и др. Чебоксары: ЦНС «Интерактив плюс», 2017a. Т. 1. С. 14-16. [Kazachkova NM. Ispol'zovanie prirodnykh antibiotikov v ratsione sel'skokhozyaistvennykh zhivotnykh i ptitsy (Conference proceedings) Innovatsionnye tekhnologii v obrazovanii i nauke: materialy Mezhdunar. nauch.-prakt. konf. (Cheboksary, 7 maya 2017 g.) redkol.: Shirokov ON et al. Cheboksary: TsNS «Interaktiv plyus»; 2017a:14-16. (In Russ)].

8. Кормовая добавка для крупного рогатого скота: пат. 2719921 Рос. Федерация / К.Н. Атландерова, А.М. Макаева, Г.К. Дускаев, С.А. Мирошников, Е.А. Сизова, И.И. Слепцов. Заявл. 19.09.19; опубл. 21.04.2020, Бюл. № 12. [Atlanderova KN, Makaeva AM, Duskaev GK, Miroshnikov SA, Sizova EA, Sleptsov II. Kormovaya dobavka dlya krupnogo rogatogo skota: pat. 2719921 Ros. Federatsiya. Zayavl. 19.09.19; opubl. 21.04.2020, Byul. № 12. (In Russ)].

9. Лебедев П.Т., Усович А.Т. Методы исследования кормов, органов и тканей животных. 3-е изд., перераб. и доп. М.: Россельхозиздат, 1976. 389 с. [Lebedev PT, Usovich AT. Metody issledovaniya kormov, organov i tkanei zhivotnykh. 3-e izd., pererab. i dop. Moscow: Rosselkhozizdat; 1976:389. (In Russ)].

10. Лукашик А.А., Тащилин В.А. Зоотехнический анализ кормов: практикум. М.: Колос, 1965. 225 c. [Lukashik AA, Tashilin VA. Zootekhnicheskii analiz kormov: praktikum. Moscow: Kolos; 1965:225. (In Russ)].

11. Макаева А.М., Атландерова К.Н. Переваримость питательных веществ корма при использовании биостимулятора экстракта коры дуба (Quercus cortex) в условиях in vitro // Животноводство и кормопроизводство. 2018. Т. 101. № 1. С. 147-153. [Makaeva AM, Atlanderova KN. Digestibility of feed nutrients after using bio-stimulant extract of oak cortex (quercus cortex) in vitro. Animal Husbandry and Fodder Production. 2018;101(1):147-153. (In Russ)].

12. Микробиом рубца крупного рогатого скота при использовании в кормлении экстракта Quercus Cortex / К.Н. Атландерова, Г.К. Дускаев, А.М. Макаева, Д.М. Муслюмова, К.С. Кондрашова // Животноводство и кормопроизводство. 2019. Т. 102. № 4. С. 186-197. [Atlanderova KN, Duskaev GK, Makaeva AM, Muslyumova DM, Kondrashova KS. Cattle rumen microbiome after Quercus Cortex extract. Animal Husbandry and Fodder Production. 2019;102(4):186-197 (In Russ)]. doi: $10.33284 / 2658-3135-102-4-186$

13. Нормы и рационы кормления сельскохозяйственных животных: справ. пособие / А.П. Калашников и др. 3-е изд., перераб. и доп. М.: Агропромиздат, 2003. 456 с. [Kalashnikov AP, et al. Normy i ratsiony kormleniya sel'skokhozyaistvennykh zhivotnykh: sprav. posobie. 3-e izd., pererab. i dop. Moscow: Agropromizdat; 2003:456 p. (In Russ)].

14. Способ экстракции из твёрдого растительного сырья композиции химических соединений для подавления зоопатогенных бактерий. пат. 2649812 Рос. Федерация / Д.Г. Дерябин, А.А. Галаджиева, С.А. Мирошников, Г.К. Дускаев, Б.Г. Рогачёв, Л.Н. Павлов. Заявл. 28.12.16; опубл. 04.04.18, Бюл. № 10. [Deryabin DG, Galadzhieva AA, Miroshnikov SA, Duskaev GK, Rogachev BG, Pavlov LN. Sposob ekstraktsii iz tverdogo rastitel'nogo syr'ya kompozitsii khimicheskikh soedinenii dlya 
podavleniya zoopatogennykh bakterii. pat. 2649812 Ros. Federatsiya. Zayavl. 28.12.16; opubl. 04.04.18, Byul. № 10. (In Russ)].

15. Швиндт В.И. Влияние перорального приёма лактобифадола на эффективность использования кальция и фосфора корма в организме животных // Вестник Оренбургского государственного университета. 2006. Приложение Биоэлементология. № 2(52). С. 93-94. [Shvindt VI. Influence of Lactobifadol oral dosing on effectiveness of fodder calcium and phosphorus using in organisms of animals. Vestnik Orenburg State University. Prilozhenie Bioelementologiya. 2006;2(52):93-94. (In Russ)].

16. Arowolo MA, He J. Use of probiotics and botanical extracts to improve ruminant production in the tropics: A review. Animal Nutrition. 2018;4(3):241-249. doi: 10.1016/j.aninu.2018.04.010

17. Asfour HZ. Anti-quorum sensing natural compounds. Journal of microscopy and ultrastructure. 2018;6(1):1-10. doi: 10.4103/JMAU.JMAU_10_18

18. Cobellis G, Trabalza-Marinucci M, Y $\mathrm{u}$ Z. Critical evaluation of essential oils as rumen modifiers in ruminant nutrition: A review. Science of the Total Environment. 2016;545-546:556-568. doi: $10.1016 /$ j.scitotenv.2015.12.103

19. Cruz OTB, Valero MV, Zawadzki F, Rivaroli DC, Prado RM, Lima BS, Prado IN. Effect of glycerine and essential oils (Anacardium occidentale and ricinus Communis) on animal performance, feed efficiency and carcass characteristics of crossbred bulls finished in a feedlot system. Italian Journal of Animal Science. 2014;13(4):790-797. doi: 10.4081/ijas.2014.3492

20. Deryabin DG, Tolmacheva AA. Antibacterial and anti-quorum sensing molecular composition derived from Quercus cortex (oak bark) extract. Molecules. 2015;20(9):17093-17108. doi: https://doi.org/10.3390/molecules200917093

21. Duskaev GK, Karimov IF, Levakhin GI, Nurzhanov BS, Rysaev AF, Dusaeva H. Ecology of ruminal microorganisms under the influence of quercus cortex extract. International Journal of Geomate. 2019;16(55):59-66. doi: 10.21660/2019.55.4673

22. Gaggia F, Mattarelli P, Biavati B. Probiotics and prebiotics in animal feeding for safe food production. International Journal of Food Microbiology. 2010;141(S):S15-S28. doi: 10.1016/j.ijfoodmicro.2010.02.031

23. Hart KJ, Yanez-Ruiz DR, Duval SM, McEwan NR, Newbold CJ. Plant extracts to manipulate rumen fermentation. Animal Feed Science and Technology. 2008;147(1-3):8-35. doi: 10.1016/j.anifeedsci.2007.09.007

24. Khan RU, Shabana N, Kuldeep D, Karthik K, Ruchi T, Mutassim MA. Direct-fed microbial: beneficial applications, modes of action and prospects as a safe tool for enhancing ruminant production and safeguarding health. International Journal of Pharmacology. 2016;12(3):220-231. doi: 10.3923/ijp.2016.220.231

25. Packiavathy IASV, Priya S, Pandian SK, Ravi AV. Inhibition of biofilm development of uropathogens by curcumin - An anti-quorum sensing agent from Curcuma longa. Food Chemistry. 2014;148:453-460. doi: 10.1016/j.foodchem.2012.08.002

26. Patra AK, Saxena J. A new perspective on the use of plant secondary metabolites to inhibit methanogenesis in the rumen. Phytochemistry. 2010;71(11-12):1198-1222. doi: 10.1016/j.phytochem.2010.05.010

27. Ponnusamy K, Paul D, Kweon JH. Inhibition of quorum sensing mechanism and Aeromonas hydrophila biofilm formation by Vanillin. Environmental engineering science. 2009;26(8):1359-1363. doi: $10.1089 /$ ees.2008.0415

28. Reti KL, Thomas MC, Yanke LJ, Selinger LB, Inglis GD. Effect of antimicrobial growth promoter administration on the intestinal microbiota of beef cattle. Gut Pathogens. 2013;5:8. doi: $10.1186 / 1757-4749-5-8$

29. Valero MV, Prado RM, Zawadzki F, Eiras CE, Madrona GS, Prado IN. Propolis and essential oils additives in the diets improved animal performance and feed efficiency of bulls finished in feedlot. Acta Scientiarum. Animal Sciences. 2014;36(4):419-426. doi: 10.4025/actascianimsci.v36i4.23856 


\section{References}

1. Krespo K. Amortized composition and a method for increasing the appetite of piglets with its help: pat. 2485801 Ros. Federation. Appl. 11/27/08; publ. 06/27/13, Byul. No. 18.

2. Akhazhanov KK. Zooanalysis of feed: textbook. a guide for Agr. specialist. Universities. Almaty: Epigraph; 2016:82 p.

3. Bagirov VA, Duskaev GK, Kazachkova NM, Rakhmatullin ShG, Yausheva EV, Kosyan DB, Makaev ShA, Dusaeva KhB. Addition of Quercus cortex extract to broiler diet changes slaughter indicators and biochemical composition of muscle tissue. Sel'skokhozyaistvennaya biologiya [Agricultural Biology]. 2018;53(4):799-810. doi: 10.15389/agrobiology.2018.4.799eng

4. Ushakov AS, Levakhin GI, Nurzhanov BS, Rysayev AF, Meshcheryakov AG. Effect of feeding with vegetative extract in combination with an enzymatic preparation on element status of ruminal microflora of cattle. Herald of Beef Cattle Breeding. 2017;3(99):120-127.

5. Fisinin VI, Ushakov AS, Duskaev GK, Kazachkova NM, Nurzhanov BS, Rakhmatullin ShG, Levakhin GI. Mixtures of biologically active substances of oak bark extracts change immunological and productive indicators of broilers. Sel'skokhozyaistvennaya biologiya [Agricultural Biology]. 2018;53(2):385-392. doi: 10.15389/agrobiology.2018.2.385eng

6. Kazachkova NM. The impact of Quercus Cortex extract on various types of metabolism in the body of farm animals and poultry (Conference proceedings) Research: theory, methodology and practice: materials of the III Intern. scientific-practical conf. (Cheboksary, November 19, 2017). editorial board: Shirokov ON et al. Cheboksary: Central nervous system "Interactive plus"; 2017b;1:12-14.

7. Kazachkova NM. The use of natural antibiotics in the diet of farm animals and poultry (Conference proceedings) Innovative technologies in education and science: materials of the Intern. scientific-practical conf. (Cheboksary, May 7, 2017). editorial board: Shirokov ON. et al. Central nervous system "Interactive plus"; 2017a:14-16.

8. Atlanderova KN, Makaeva AM, Duskaev GK, Miroshnikov SA, Sizova EA, Sleptsov II. Feed additive for cattle: pat. 2719921 Rus. Federation. Appl. 09/19/19; publ. 04/21/2020, Buyl. No. 12.

9. Lebedev PT, Usovich AT. Research methods for animal feed, organs and tissues. 3rd ed., Rev. and add. Moscow: Rosselkhozizdat; 1976:389 p.

10. Lukashik AA, Tashilin VA. Zootechnical analysis of feed: practicum. Moscow: Kolos; 1965:225.

11. Makaeva AM, Atlanderova KN. Digestibility of feed nutrients after using bio-stimulant extract of oak cortex (quercus cortex) in vitro. Animal Husbandry and Fodder Production. 2018;101(1):147-153.

12. Atlanderova KN, Duskaev GK, Makaeva AM, Muslyumova DM, Kondrashova KS. Cattle rumen microbiome after Quercus Cortex extract. Animal Husbandry and Fodder Production. 2019;102(4):186-197 doi: 10.33284/2658-3135-102-4-186

13. Kalashnikov AP et al. Standards and diets of farm animals: Ref. book. 3rd ed., rework. and add. Moscow: Agropromizdat; 2003:456 p.

14. Deryabin DG, Galadzhieva AA, Miroshnikov SA, Duskaev GK, Rogachev BG, Pavlov LN. A method of extracting a composition of chemical compounds from solid plant raw materials to suppress zoopathogenic bacteria: pat. 2649812 Rus. Federation. Appl. 12/28/16; publ. 04.04.18, Byul. No. 10.

15. Shvindt VI. Influence of Lactobifadol oral dosing on effectiveness of fodder calcium and phosphorus using in organisms of animals. Vestnik Orenburg State University. Application Bioelementology. 2006;2(52):93-94.

16. Arowolo MA, He J. Use of probiotics and botanical extracts to improve ruminant production in the tropics: A review. Animal Nutrition. 2018;4(3):241-249. doi: 10.1016/j.aninu.2018.04.010

17. Asfour HZ. Anti-quorum sensing natural compounds. Journal of microscopy and ultrastructure. 2018;6(1):1-10. doi: 10.4103/JMAU.JMAU_10_18

18. Cobellis G, Trabalza-Marinucci M, Y $\bar{u}$ Z. Critical evaluation of essential oils as rumen modifiers in ruminant nutrition: A review. Science of the Total Environment. 2016;545-546:556-568. doi: $10.1016 /$ j.scitotenv.2015.12.103 
19. Cruz OTB, Valero MV, Zawadzki F, Rivaroli DC, Prado RM, Lima BS, Prado IN. Effect of glycerine and essential oils (Anacardium occidentale and ricinus Communis) on animal performance, feed efficiency and carcass characteristics of crossbred bulls finished in a feedlot system. Italian Journal of Animal Science. 2014;13(4):790-797. doi: 10.4081/ijas.2014.3492

20. Deryabin DG, Tolmacheva AA. Antibacterial and anti-quorum sensing molecular composition derived from Quercus cortex (oak bark) extract. Molecules. 2015;20(9):17093-17108. doi: https://doi.org/10.3390/molecules200917093

21. Duskaev GK, Karimov IF, Levakhin GI, Nurzhanov BS, Rysaev AF, Dusaeva H. Ecology of ruminal microorganisms under the influence of quercus cortex extract. International Journal of Geomate. 2019;16(55):59-66. doi: 10.21660/2019.55.4673

22. Gaggia F, Mattarelli P, Biavati B. Probiotics and prebiotics in animal feeding for safe food production. International Journal of Food Microbiology. 2010;141(S):S15-S28. doi: 10.1016/j.ijfoodmicro.2010.02.031

23. Hart KJ, Yanez-Ruiz DR, Duval SM, McEwan NR, Newbold CJ. Plant extracts to manipulate rumen fermentation. Animal Feed Science and Technology. 2008;147(1-3):8-35. doi: 10.1016/j.anifeedsci.2007.09.007

24. Khan RU, Shabana N, Kuldeep D, Karthik K, Ruchi T, Mutassim MA. Direct-fed microbial: beneficial applications, modes of action and prospects as a safe tool for enhancing ruminant production and safeguarding health. International Journal of Pharmacology. 2016;12(3):220-231. doi: 10.3923/ijp.2016.220.231

25. Packiavathy IASV, Priya S, Pandian SK, Ravi AV. Inhibition of biofilm development of uropathogens by curcumin - An anti-quorum sensing agent from Curcuma longa. Food Chemistry. 2014;148:453-460. doi: 10.1016/j.foodchem.2012.08.002

26. Patra AK, Saxena J. A new perspective on the use of plant secondary metabolites to inhibit methanogenesis in the rumen. Phytochemistry. 2010;71(11-12):1198-1222. doi: 10.1016/j.phytochem.2010.05.010

27. Ponnusamy K, Paul D, Kweon JH. Inhibition of quorum sensing mechanism and Aeromonas hydrophila biofilm formation by Vanillin. Environmental engineering science. 2009;26(8):1359-1363. doi: $10.1089 /$ ees.2008.0415

28. Reti KL, Thomas MC, Yanke LJ, Selinger LB, Inglis GD. Effect of antimicrobial growth promoter administration on the intestinal microbiota of beef cattle. Gut Pathogens. 2013;5:8. doi: 10.1186/1757-4749-5-8

29. Valero MV, Prado RM, Zawadzki F, Eiras CE, Madrona GS, Prado IN. Propolis and essential oils additives in the diets improved animal performance and feed efficiency of bulls finished in feedlot. Acta Scientiarum. Animal Sciences. 2014;36(4):419-426. doi: 10.4025/actascianimsci.v36i4.23856

Кондрашова Кристина Сергеевна, младший научный сотрудник лаборатории селекционно-генетических исследований в животноводстве, Федеральный научный центр биологических систем и агротехнологий Российской академии наук, г. Оренбург, ул. 9 Января, 29; тел.: +79228408002, e-mail: christinakondrashova94@yandex.ru

Косян Дианна Багдасаровна, кандидат биологических наук, и.о. заведующего лабораторией селекционно-генетических исследований в животноводстве, Федеральный научный центр биологических систем и агротехнологий Российской академии наук, 460000, г. Оренбург, ул. 9 Января, 29, тел.: +79228448915, e-mail: kosyan.diana@mail.ru

Атландерова Ксения Николаевна, кандидат биологических наук, младший научный сотрудник Испытательного центра ЦКП, Федеральный научный центр биологических систем и агротехнологий Российской академии наук, 460000, г. Оренбург, ул. 9 Января, 29, тел.: +79228134865, e-mail: atlander-kn@mail.ru

Поступила в редакцию 12 ноября 2020 г.; принята после решения редколлегии 14 декабря 2020 г.; опубликована 31 декабря 2020 г. / Received: 12 November 2020; Accepted: 14 December 2020;

Published: 31 December 2020 